\title{
Physiological Concentrations of Serum Cortisol Are Related to Vascular Risk Markers in Prepubertal Children
}

\author{
PILAR SORIANO-RODRÍGUEZ, INÉS OSINIRI, PILAR GRAU-CABRERA, ELENA RIERA-PÉREZ, ANNA PRATS-PUIG, \\ MÍRIAM CARBONELL-ALFEREZ, STEPHAN SCHNEIDER, CARME MORA-MARUNY, FRANCIS DE ZEGHER, \\ LOURDES IBÁNEZ, JUDIT BASSOLS, AND ABEL LÓPEZ-BERMEJO
}

\begin{abstract}
Clinical Laboratory [P.S.-R., C.M.-M.], Department of Pediatrics [I.O., P.G.-C., E.R.-P. M.C.-A., S.S.], Salut Empordà Foundation, 17600 Figueres, Spain; Department of Pediatrics [A.P.-P., J.B., A.L.-B.], Dr. Josep Trueta Hospital, 17007 Girona, Spain; Girona Institute for Biomedical Research [A.P.-P., J.B., A.L.-B.], 17007 Girona, Spain; Department of Woman \& Child [F.Z.], University of Leuven, 3000 Leuven, Belgium; Endocrinology Unit [L.I.], Sant Joan de Déu Children's Hospital, University of Barcelona, 08950 Esplugues, Barcelona, Spain
\end{abstract}

\begin{abstract}
There is increasing evidence that cortisol contributes to cardiovascular risk. It is unclear whether physiological concentrations of serum cortisol are related to vascular risk markers in children. The cross-sectional associations between morning serum cortisol and cardiovascular risk markers: blood pressure (BP) and carotid intima-media thickness (IMT), were examined in a sample of healthy prepubertal children (age, $6.8 \pm 0.1 \mathrm{y}$ ) attending primary care clinics. Serum cortisol was associated with increased systolic BP (SBP; $n=223 ; p<0.001)$ and carotid IMT $(n=91 ; p<0.0001)$. These associations were independent from age, BMI, body fat, waist, insulin resistance, serum lipids, and heart rate (HR). No gender interactions were apparent in these associations. In summary, a higher morning serum cortisol within the physiological range is in prepubertal children associated with vascular risk markers. Because childhood risk factors predict adult risk for cardiovascular disease, these observations may have implications in the prevention of cardiovascular disease early in life. (Pediatr Res 68: 452-455, 2010)
\end{abstract}

$I^{\prime}$ is well recognized that hypercortisolemia predisposes to a dysmetabolic phenotype, with accumulation of visceral fat, hyperglycemia, insulin resistance, decreased HDL (C), increased triglycerides, and high blood pressure (BP) (1).

Glucocorticoids have long been recognized to be essential for maintenance of normal BP and, when in excess, either generally or locally, produce hypertension (2). An association between cortisol and both systolic BP (SBP) and diastolic BP (DBP) has been reported by different authors $(1,3,4)$. Discussion exists as to whether prenatal growth may mediate these associations $(3,5)$.

There is considerable interest in the notion that cortisol may play a role in some forms of essential hypertension, and it has been suggested that a higher cortisol production may contribute to $\sim 30 \%$ of all cases of hypertension $(6-8)$. Recent data indicate that hypercortisolemia may induce hypertension by

Received February 3, 2010; accepted June 18, 2010.

Correspondence: Abel López-Bermejo, M.D., Pediatric Endocrinology, Dr. Josep Trueta Hospital, Av. França s/n, 17007 Girona, Spain; e-mail: alopezbermejo.girona. ics@gencat.cat

This study was supported in part by grant no. 07/0404 from the National Institute of Health Carlos III (Fund for Health Research FIS, Spain), by grant "Premi Àmbit de la Infància 2008" from Fundació Agrupació Mútua, and the Fund for Scientific Research I3 from the Ministry of Science and Innovation (Spain) [to A.L.-B.]. Additional support was received from the Fund for Scientific Research (Belgium) [to F.Z.], the National Institute of Health Carlos III (Spain) [to L.I. and J.B.]. an up-regulation of oxidative stress and impairment of NO availability (9).

Several studies suggested that cortisol may play a role in the development of atherosclerosis (10,11). Smith et al. (12) found an association between cortisol and incident ischemic heart disease. Eller et al. (13) described associations between salivary cortisol and progression in carotid intima-media thickness (IMT), a preclinical marker of atherosclerosis, in women. In adolescents with insulin-dependent diabetes mellitus, carotid IMT was shown to be increased and to be related to higher urinary free cortisol (14).

However, the contribution of physiological variations in serum cortisol to vascular risk markers in children is largely unknown. Because childhood risk factors predict adult risk for cardiovascular disease (15), it is important to identify these risk factors early in life. We posited that morning serum cortisol is an early risk factor for cardiovascular disease. In this study, we examined the cross-sectional associations between morning serum cortisol and vascular risk markers: BP and carotid IMT, in a sample of healthy prepubertal children.

\section{SUBJECTS AND METHODS}

Population and ethics. The study group consisted of 223 school-aged healthy Caucasian children (106 boys and 117 girls; age, $6.8 \pm 0.1 \mathrm{y}$ ). Subjects were included in a study of cardiovascular risk factors in children and were consecutively recruited among those seen for well-child check-up visits by their primary care pediatricians in Alt Empordà, a region in Northern Spain. Participation ranged from 50 to $70 \%$ among the different clinics. All children were apparently healthy and their morning serum cortisol levels were within normal values (16).

Inclusion criteria were 1) age between 5 and $9 \mathrm{y}$ and 2) absence of puberty, as based on the standards by Marshall and Tanner. Exclusion criteria were as follows: 1) major congenital abnormalities; 2) abnormal blood counts, liver or kidney or thyroid functions; 3 ) evidence of chronic illness or chronic use of medication; and 4) acute illness or medication use within the previous month of inclusion.

The research was approved by the Institutional Review Board of Dr. Josep Trueta Hospital. Signed consent was obtained from the parents.

Clinical assessments. Clinical examination was performed in the morning, in the fasting state followed by venous blood sampling. A local anesthetic cream was used to minimize the discomfort of venipuncture. Weight was measured wearing light clothes with a calibrated scale, and height was measured with a Harpenden stadiometer. BMI was calculated as weight

Abbreviations: BP, blood pressure; HR, heart rate; IMT, intima-media thickness; SBP, systolic blood pressure; SDS, SD score 
Table 1. Clinical and laboratory variables in subjects with carotid IMT measurements $(n=91)$

\begin{tabular}{lcc}
\hline & Boys $(n=43)$ & Girls $(n=48)$ \\
\hline Clinical assessments & & \\
Age (yr) & $6.9 \pm 0.2$ & $7.0 \pm 0.2$ \\
Weight (kg) & $26.4 \pm 1.2$ & $26.0 \pm 1.0$ \\
Height (cm) & $123.3 \pm 1.6$ & $122.7 \pm 1.2$ \\
BMI (kg/m $\left.{ }^{2}\right)$ & $17.04 \pm 0.5$ & $17.06 \pm 0.4$ \\
BMI SDS & $0.1 \pm 0.2$ & $0.1 \pm 0.2$ \\
Fat mass (\%) & $28.0 \pm 0.9$ & $33.1 \pm 1.0$ \\
Waist (cm) & $54.5 \pm 1.2$ & $55.7 \pm 1.1$ \\
SBP (mm Hg) & $101 \pm 2$ & $103 \pm 1$ \\
DBP (mm Hg) & $55 \pm 1$ & $58 \pm 1$ \\
HR (bpm) & $79 \pm 1$ & $83 \pm 2$ \\
Carotid IMT (mm) & $0.043 \pm 0.001$ & $0.041 \pm 0.001$ \\
Laboratory variables & & \\
Fasting glucose (mg/dL) & $87 \pm 1$ & $84 \pm 1$ \\
Fasting insulin (mIU/L) & $2.4 \pm 0.5$ & $3.1 \pm 0.7$ \\
HOMA-IR & $0.49 \pm 0.1$ & $0.66 \pm 0.2$ \\
Triacylglycerides (mg/dL) & $54 \pm 3$ & $57 \pm 2$ \\
HDL cholesterol (mg/dL) & $57 \pm 2$ & $57 \pm 2$ \\
Cortisol (mg/dL)* & $16.3 \pm 0.8$ & $16.0 \pm 0.8$ \\
\hline
\end{tabular}

Data are presented as mean \pm SEM. Comparisons of the distribution of variables in the study subjects $(n=223)$ and in those with IMT measurements $(n=91)$ were all at $p>0.05$.

* Reference values in boys: $2.0-31.8 \mathrm{mg} / \mathrm{dL}$; in girls: $1.2-29.0 \mathrm{mg} / \mathrm{dL}$ (16).

divided by the square of height in meters. Age- and sex-adjusted SD scores (SDS) for BMI were calculated using regional normative data. Waist circumference was measured in the supine position at the umbilical level.

$\mathrm{BP}$ and heart rate (HR) were measured before venous blood sampling in the supine position on the right arm after a 10-min rest; an electronic sphygmomanometer (Dinamap Pro 100; GE Healthcare, Chalfont St. Giles, United Kingdom) with cuff size appropriate for arm circumference was used. Two to three measurements were taken in each individual, and results were averaged.

Body composition was assessed by bioelectric impedance (Hydra Bioimpedance Analyzer 4200; Xitron Technologies, San Diego, CA). Fat mass was calculated as the difference between weight and lean mass.

Intima-media thickness. In a subset of subjects $(n=91)$ who agreed to participate further in the study and whose clinical characteristics did not diverge from the whole group (Table 1), carotid IMT was measured by high-resolution ultrasonography (MyLab25; Esaote, Florence, Italy) using a linear $12-\mathrm{MHz}$ transducer. Diastolic images were obtained on the right side at the level of the distal common carotid artery, $1 \mathrm{~cm}$ away from its bifurcation. Averages of five IMT measurements on the far wall of the artery were used in the study. All IMT measurements were taken on a separate visit in all children and were performed by the same observer who was blinded to the clinical and laboratory characteristics of the subjects. Intrasubject coefficient of variation for IMT measurements was $<6 \%$.

Laboratory variables. All serum samples were obtained between 0800 and $0900 \mathrm{~h}$ under fasting conditions. Serum glucose was analyzed by the hexokinase method. Serum immunoreactive insulin was measured by immunochemiluminiscence (IMMULITE 2000; Diagnostic Products, Los Angeles, CA). Lower detection limit was $0.4 \mathrm{mIU} / \mathrm{L}$ and intra- and interassay CVs were $<10 \%$. Insulin resistance was calculated using the homeostasis model assessment for insulin resistance [HOMA-IR = (fasting insulin in $\mathrm{mU} / \mathrm{L}) \times($ fasting glucose in $\mathrm{mM}$ )/22.5]. Total serum triglycerides were measured by monitoring the reaction of glycerol-phosphate-oxidase and peroxidase. HDL (C) was quantified by means of the homogenous-accelerator selective detergent method. Cortisol was measured by a fluorescence polarization immunoassay (FPIA; AxSYM, ABBOTT, Abbott Park, IL). Lower detection limit was 1.1 $\mu \mathrm{g} / \mathrm{dL}$, and intra- and interassay CVs were $<10 \%$.

Statistics. Statistical analyses were performed using SPSS version 12.0 (SPSS Inc, Chicago, IL). Results are expressed as mean \pm SEM. Nonparametric variables were mathematically transformed to improve symmetry. The relation between variables was analyzed by simple correlation followed by multiple regression analysis in a stepwise manner. Significance level was set at $p<0.05$. The study had an $80 \%$ power to detect a significant association between serum cortisol and IMT with a Pearson correlation coefficient of 0.26 in the studied subjects.
Table 2. Clinical and laboratory variables in the studied subjects

\begin{tabular}{lcc}
\hline & Boys $(n=106)$ & Girls $(n=117)$ \\
\hline Clinical assessments & & \\
Age (yr) & $6.8 \pm 0.1$ & $6.8 \pm 0.1$ \\
Weight $(\mathrm{kg})$ & $25.4 \pm 0.7$ & $25.5 \pm 0.6$ \\
Height $(\mathrm{cm})$ & $122.0 \pm 0.9$ & $121.3 \pm 0.8$ \\
BMI $\left(\mathrm{kg} / \mathrm{m}^{2}\right)$ & $16.78 \pm 0.3$ & $17.08 \pm 0.3$ \\
BMI SDS & $0.0 \pm 0.1$ & $0.1 \pm 0.1$ \\
Fat mass $(\%)$ & $28.2 \pm 0.5$ & $33.8 \pm 0.6^{*}$ \\
Waist $(\mathrm{cm})$ & $54.7 \pm 0.7$ & $55.7 \pm 0.7$ \\
SBP $(\mathrm{mm} \mathrm{Hg})$ & $101 \pm 1$ & $102 \pm 1$ \\
DBP (mm Hg) & $56 \pm 1$ & $58 \pm 1 \dagger$ \\
HR (bpm) & $79 \pm 1$ & $84 \pm 1^{*}$ \\
Carotid IMT (mm) $n=91$ & $0.043 \pm 0.001$ & $0.041 \pm 0.001$ \\
$\quad(43$ boys and 48 girls) & & \\
Laboratory variables & $87 \pm 1$ & $85 \pm 1 \ddagger$ \\
Fasting glucose (mg/dL) & $2.1 \pm 0.2$ & $3.3 \pm 0.4^{*}$ \\
Fasting insulin (mIU/L) & $0.45 \pm 0.1$ & $0.71 \pm 0.1^{*}$ \\
HOMA-IR & $53 \pm 2$ & $57 \pm 2$ \\
Triacylglycerides (mg/dL) & $57 \pm 1$ & $53 \pm 1 \dagger$ \\
HDL cholesterol (mg/dL) & $16.0 \pm 0.5$ & $14.8 \pm 0.5$ \\
Cortisol (mg/dL) $\S$ &
\end{tabular}

Data are presented as mean \pm SEM.

$* p<0.001$ as compared with boys by $t$ test.

$\ddagger p<0.05$ as compared with boys by $t$ test.

$\dagger p<0.01$ as compared with boys by $t$ test.

$\S$ Reference values in boys, $2.0-31.8 \mathrm{mg} / \mathrm{dL}$; in girls, $1.2-29.0 \mathrm{mg} / \mathrm{dL}$ (16).

\section{RESULTS}

Clinical and laboratory characteristics of the studied subjects are summarized in Table 2. Serum cortisol was related to BMI SDS $(r=-0.23, p<0.001)$, both SBP $(r=0.21, p<$ 0.005 ; Fig. 1$)$ and DBP $(r=0.14, p<0.05)$, HR $(r=0.14$, $p<0.05)$, and carotid IMT $(r=0.38, p<0.001$; Fig. 1$)$ in the studied subjects. No gender or BMI interactions were apparent in the associations with SBP and carotid IMT. Serum cortisol was unrelated to age, body fat, waist, insulin resistance, or serum lipids.

In multiple regression analyses (Table 3), serum cortisol together with HOMA-IR, HR, and waist contributed to $23 \%$ of SBP variance, and serum cortisol and BMI contributed to $19 \%$ of carotid IMT variance in the studied subjects. The independent associations with SBP and carotid IMT were evident in both genders.

\section{DISCUSSION}

Physiological concentrations of serum cortisol were related to both SBP and carotid IMT in prepubertal boys and girls. Although the association between serum cortisol and visceral fat is well accepted (17-20), the impact of total body adiposity on serum cortisol is less clear, with some reports showing positive $(5,21)$ and others negative associations between obesity measures and serum, salivary, or urine cortisol $(3,22)$. These differences may be explained, in part, by the selection criteria and clinical characteristics of the studied subjects (i.e. obese versus nonobese subjects), because increased body weight is known to be associated with not only increased cortisol production but also increased cortisol clearance rate (23). In our study, higher BMI was independently associated 
with lower serum cortisol concentrations in unselected healthy prepubertal children.

A number of studies have reported on the association between cortisol and BP $(3,4,8,24,25)$. However, little is known about the effects of physiological variations in serum cortisol concentrations on BP in children. Our findings show
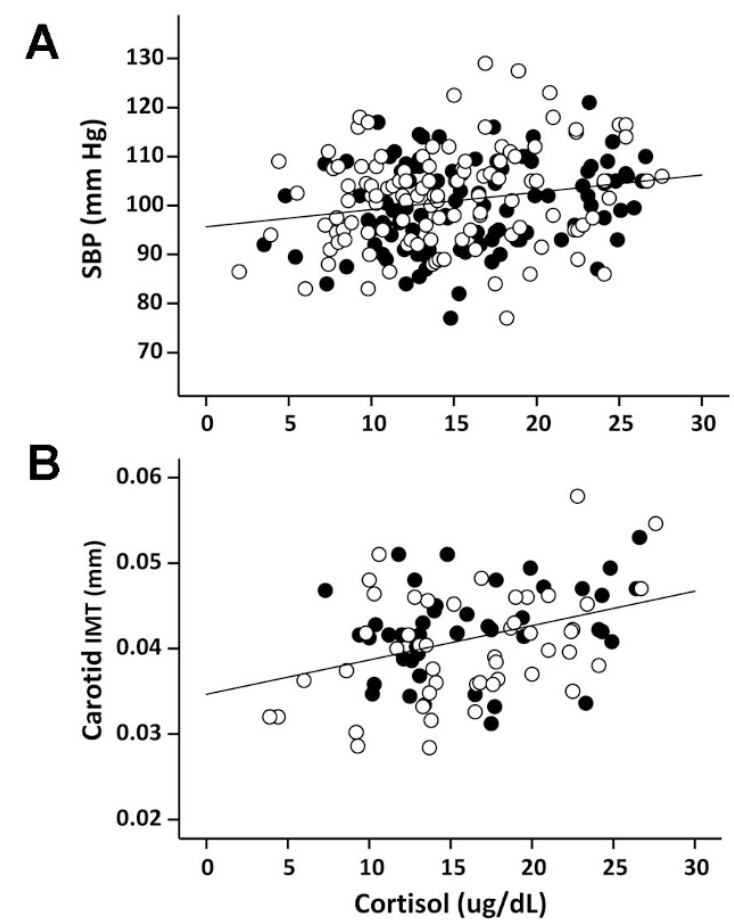

Figure 1. Correlation graphs of morning serum cortisol with both $(A)$ SBP $(n=223, r=0.189, p<0.005)$ and $(B)$ carotid IMT $(n=91, r=0.361, p<$ $0.0005)$ in healthy prepubertal children. $\bigcirc$ : boys; $\bigcirc$ : girls. The $r$ and $p$ values (Pearson analyses) are for all children as a group. that higher cortisol concentrations within the normal range are associated with higher SBP. These associations were independent from age, BMI, body fat, waist, insulin resistance, serum lipids, and HR. Although a possible role of a stress response mediating these associations cannot be excluded, the fact that they persisted after adjusting for HR points to additional mechanisms in the relationship between serum cortisol and vascular risk markers. It has been proposed that prenatal growth restriction may program the adrenal axis for an exaggerated stress response, and we cannot exclude the possibility that the observations herein described are related to prenatal programming of the adrenal axis (3). In support of this hypothesis, a recent report from a birth cohort study has shown that cord-blood cortisol predicts a higher BP at age of 3 y (26).

Besides BP, carotid IMT is a well-recognized vascular risk marker in both adults (27) and children (28). To the best of our knowledge, ours is the first study to show an independent association between serum cortisol and IMT in healthy children, thereby suggesting that serum cortisol is not only associated with functional but also with anatomical changes in the vasculature.

No gender interactions were apparent in these associations, and therefore, our data are consistent with studies showing that the sexual dimorphism in cortisol secretion starts after the age of $10 \mathrm{y}$ in healthy children (29). However, the vascular risk markers studied were differentially associated with obesity measures and insulin resistance in our study. Differences in the pathogenesis of vascular dysfunction may therefore exist in males and females (30).

The mechanisms by which higher cortisol can contribute to cardiovascular disease may include both systemic and local effects of the hormone (31). It is well recognized that hypercortisolemia predisposes to a dysmetabolic phenotype by im-

Table 3. Multivariate linear models of carotid IMT, SBP, and DBP as dependent variables

\begin{tabular}{|c|c|c|c|c|c|c|c|c|c|}
\hline & \multicolumn{3}{|c|}{ Carotid IMT } & \multicolumn{3}{|c|}{ SBP } & \multicolumn{3}{|c|}{ DBP } \\
\hline & Beta & Significance & $95 \% \mathrm{CI}$ & Beta & Significance & $95 \% \mathrm{CI}$ & Beta & Significance & $95 \% \mathrm{CI}$ \\
\hline \multicolumn{10}{|l|}{$\begin{array}{l}\text { All subjects } \\
\qquad(n=223) *\end{array}$} \\
\hline Cortisol & 0.001 & $<0.0001$ & $0.000-0.001$ & 0.453 & $<0.001$ & $0.187-0.719$ & - & - & - \\
\hline BMI & 0.001 & $<0.005$ & $0.000-0.001$ & - & - & - & - & - & - \\
\hline Waist & - & - & - & 0.321 & $<0.01$ & $0.089-0.554$ & - & - & - \\
\hline Log10 HOMA-IR & - & - & - & 4.442 & $<0.05$ & $0.704-8.179$ & 3.213 & $<0.005$ & $0.989-5.437$ \\
\hline $\mathrm{HR}$ & - & - & - & 0.187 & $<0.01$ & $0.075-0.298$ & 0.237 & $<0.0001$ & $0.162-0.312$ \\
\hline \multicolumn{10}{|l|}{ Boys $(n=106) \dagger$} \\
\hline Cortisol & 0.001 & $<0.05$ & $0.000-0.001$ & 0.419 & $<0.05$ & $0.006-0.807$ & - & - & - \\
\hline Log10 HOMA-IR & - & - & - & 5.880 & $<0.001$ & $0.180-11.087$ & 4.603 & $<0.01$ & $1.101-8.104$ \\
\hline $\mathrm{HR}$ & - & - & - & - & - & - & 0.219 & $<0.0001$ & $0.115-0.323$ \\
\hline \multicolumn{10}{|l|}{ Girls $(n=117) \ddagger$} \\
\hline Cortisol & 0.001 & $<0.001$ & $0.000-0.001$ & 0.600 & $<0.005$ & $0.201-0.999$ & - & - & - \\
\hline BMI & 0.001 & $<0.01$ & $0.000-0.001$ & - & - & - & - & - & - \\
\hline Waist & - & - & - & 0.354 & $<0.01$ & $0.080-0.628$ & - & - & - \\
\hline HR & - & - & - & 0.212 & $<0.05$ & $0.018-0.405$ & 0.236 & $<0.0001$ & $0.119-0.352$ \\
\hline
\end{tabular}

$* R^{2}$ for carotid IMT: $19 \%$ (cortisol 12\%, BMI 7\%). $R^{2}$ for SBP: $23 \%$ (cortisol 7\%, waist 3\%, HOMA-IR 8\%, HR 5\%). $R^{2}$ for DBP: $24 \%$ (log 10 HOMA-IR $4 \%$ and HR 20\%). Beta coefficients are nonstandardized. Data are adjusted for age and sex. Additional nonpredictive variables (not included in the final models): fat mass and serum lipids.

$\dagger R^{2}$ for carotid IMT: $6 \% \cdot R^{2}$ for SBP: $20 \%$ (cortisol 6\%, $\log 10$ HOMA-IR 14\%). $R^{2}$ for DBP: $26 \%$ (log10 HOMA-IR 6\%, HR 20\%). Beta coefficients are nonstandardized. Data are age-adjusted. Additional nonpredictive variables (not included in the final models): BMI, fat mass, waist, and serum lipids.

$\ddagger R^{2}$ for carotid IMT: $25 \%$ (cortisol $16 \%$; BMI $9 \%$ ). $R^{2}$ for SBP: $20 \%$ (cortisol $12 \%$, waist $4 \%$, HR $4 \%$ ). $R^{2}$ for DBP: $16 \%$. Beta coefficients are nonstandardized. Data are age adjusted. Additional nonpredictive variables (not included in the final models): fat mass, log10 HOMA-IR, and serum lipids. 
pairing liver, adipose tissue, pancreas, and muscle function (32). In addition, glucocorticoids have direct effects on vascular smooth muscle cells and indirect effects promoting an increase in vascular tone in response to various vasoactive hormones (33-35). Finally, increased local cortisol levels in the blood vessels may promote perivascular inflammation $(31,34)$.

Serum cortisol changes rapidly after awakening and shows a clear diurnal variation (36). In our study, all children were assessed beyond $30 \mathrm{~min}$ of awakening, and blood was sampled in a short time frame in the morning in all subjects.

In conclusion, physiological concentrations of serum cortisol are associated with vascular risk markers as early as in childhood. Because childhood risk factors predict adult risk for cardiovascular disease, these observations may have implications in the prevention of cardiovascular disease early in life.

Acknowledgment. We are grateful to all the children and parents who took part in the study.

\section{REFERENCES}

1. Ward AM, Fall CH, Stein CE, Kumaran K, Veena SR, Wood PJ, Syddall HE, Phillips DI 2003 Cortisol and the metabolic syndrome in South Asians. Clin Endocrinol (Oxf) 58:500-505

2. Kelly JJ, Tam SH, Williamson PM, Lawson J, Whitworth JA 1998 The nitric oxide system and cortisol-induced hypertension in humans. Clin Exp Pharmacol Physiol 25:945-946

3. Phillips DI, Barker DJ, Fall CH, Seckl JR, Whorwood CB, Wood PJ, Walker BR 1998 Elevated plasma cortisol concentrations: a link between low birth weight and the insulin resistance syndrome? J Clin Endocrinol Metab 83:757-760

4. Weigensberg MJ, Toledo-Corral CM, Goran MI 2008 Association between the metabolic syndrome and serum cortisol in overweight Latino youth. J Clin Endocrinol Metab 93:1372-1378

5. Honour JW, Jones R, Leary S, Golding J, Ong KK, Dunger DB 2007 Relationships of urinary adrenal steroids at age 8 years with birth weight, postnatal growth, blood pressure, and glucose metabolism. J Clin Endocrinol Metab 92:4340-4345

6. Walker BR, Yau JL, Brett LP, Seckl JR, Monder C, Williams BC, Edwards CR 1991 11 beta-hydroxysteroid dehydrogenase in vascular smooth muscle and heart: implications for cardiovascular responses to glucocorticoids. Endocrinology 129:33053312

7. Soro A, Ingram MC, Tonolo G, Glorioso N, Fraser R 1995 Evidence of coexisting changes in 11 beta-hydroxysteroid dehydrogenase and 5 beta-reductase activity in subjects with untreated essential hypertension. Hypertension 25:67-70

8. Litchfield WR, Hunt SC, Jeunemaitre X, Fisher ND, Hopkins PN, Williams RR, Corvol P, Williams GH 1998 Increased urinary free cortisol: a potential intermediate phenotype of essential hypertension. Hypertension 31:569-574

9. Ong SL, Zhang Y, Whitworth JA 2008 Reactive oxygen species and glucocorticoidinduced hypertension. Clin Exp Pharmacol Physiol 35:477-482

10. Alevizaki M, Cimponeriu A, Lekakis J, Papamichael C, Chrousos GP 2007 High anticipatory stress plasma cortisol levels and sensitivity to glucocorticoids predict severity of coronary artery disease in subjects undergoing coronary angiography. Metabolism 56:222-226

11. Dekker MJ, Koper JW, van Aken MO, Pols HA, Hofman A, de Jong FH, Kirschbaum C, Witteman JC, Lamberts SW, Tiemeier H 2008 Salivary cortisol is related to atherosclerosis of carotid arteries. J Clin Endocrinol Metab 93:3741-3747

12. Smith GD, Ben-Shlomo Y, Beswick A, Yarnell J, Lightman S, Elwood P 2005 Cortisol, testosterone, and coronary heart disease: prospective evidence from the Caerphilly study. Circulation 112:332-340

13. Eller NH, Netterstrom B, Allerup P 2005 Progression in intima media thickness-the significance of hormonal biomarkers of chronic stress. Psychoneuroendocrinology 30:715-723
14. Peppa-Patrikiou M, Scordili M, Antoniou A, Giannaki M, Dracopoulou M, DacouVoutetakis C 1998 Carotid atherosclerosis in adolescents and young adults with IDDM. Relation to urinary endothelin, albumin, free cortisol, and other factors. Diabetes Care 21:1004-1007

15. Berenson GS 2002 Childhood risk factors predict adult risk associated with subclinical cardiovascular disease. The Bogalusa Heart Study. Am J Cardiol 90:3L-7L

16. Cortés-Blanco A, Ferrández Longás A, Mayayo Dehesa E, Labarta Aizpún JI, Martínez-Lázaro R 2000 [Hormonal reference values for adrenocortical function in healthy children from Zaragoza]. An Esp Pediatr 52:106-115

17. Therrien F, Drapeau V, Lalonde J, Lupien SJ, Beaulieu S, Tremblay A, Richard D 2007 Awakening cortisol response in lean, obese, and reduced obese individuals: effect of gender and fat distribution. Obesity (Silver Spring) 15:377-385

18. Barat P, Gayard-Cros M, Andrew R, Corcuff JB, Jouret B, Barthe N, Perez P, Germain C, Tauber M, Walker BR, Mormede P, Duclos M 2007 Truncal distribution of fat mass, metabolic profile and hypothalamic-pituitary adrenal axis activity in prepubertal obese children. J Pediatr 150:535-539, 539.e1

19. Misra M, Bredella MA, Tsai P, Mendes N, Miller KK, Klibanski A 2008 Lower growth hormone and higher cortisol are associated with greater visceral adiposity, intramyocellular lipids, and insulin resistance in overweight girls. Am J Physiol Endocrinol Metab 295:E385-E392

20. Purnell JQ, Kahn SE, Samuels MH, Brandon D, Loriaux DL, Brunzell JD 2009 Enhanced cortisol production rates, free cortisol, and 11beta-HSD-1 expression correlate with visceral fat and insulin resistance in men: effect of weight loss. Am J Physiol Endocrinol Metab 296:E351-E357

21. Reinehr T, Andler W 2004 Cortisol and its relation to insulin resistance before and after weight loss in obese children. Horm Res 62:107-112

22. Walker BR, Soderberg S, Lindahl B, Olsson T 2000 Independent effects of obesity and cortisol in predicting cardiovascular risk factors in men and women. J Intern Med 247:198-204

23. Purnell JQ, Brandon DD, Isabelle LM, Loriaux DL, Samuels MH 2004 Association of 24-hour cortisol production rates, cortisol-binding globulin, and plasma-free cortisol levels with body composition, leptin levels, and aging in adult men and women. J Clin Endocrinol Metab 89:281-287

24. Filipovsky J, Ducimetiere P, Eschwege E, Richard JL, Rosselin G, Claude JR 1996 The relationship of blood pressure with glucose, insulin, heart rate, free fatty acids and plasma cortisol levels according to degree of obesity in middle-aged men. J Hypertens 14:229-235

25. Rosmond R, Dallman MF, Bjorntorp P 1998 Stress-related cortisol secretion in men: relationships with abdominal obesity and endocrine, metabolic and hemodynamic abnormalities. J Clin Endocrinol Metab 83:1853-1859

26. Huh SY, Andrew R, Rich-Edwards JW, Kleinman KP, Seckl JR, Gillman MW 2008 Association between umbilical cord glucocorticoids and blood pressure at age 3 years. BMC Med 6:25

27. Bots ML, Hoes AW, Koudstaal PJ, Hofman A, Grobbee DE 1997 Common carotid intima-media thickness and risk of stroke and myocardial infarction: the Rotterdam Study. Circulation 96:1432-1437

28. Pauciullo P, Iannuzzi A, Sartorio R, Irace C, Covetti G, Di Costanzo A, Rubba P 1994 Increased intima-media thickness of the common carotid artery in hypercholesterolemic children. Arterioscler Thromb 14:1075-1079

29. Wudy SA, Hartmann MF, Remer T 2007 Sexual dimorphism in cortisol secretion starts after age 10 in healthy children: urinary cortisol metabolite excretion rates during growth. Am J Physiol Endocrinol Metab 293:E970-E976

30. Jones A, Beda A, Osmond C, Godfrey KM, Simpson DM, Phillips DI 2008 Sex-specific programming of cardiovascular physiology in children. Eur Heart J 29:2164-2170

31. Walker BR 2007 Glucocorticoids and cardiovascular disease. Eur J Endocrinol 157:545-559

32. Bjorntorp P, Holm G, Rosmond R 1999 Hypothalamic arousal, insulin resistance and type 2 diabetes mellitus. Diabet Med 16:373-383

33. Mangos GJ, Walker BR, Kelly JJ, Lawson JA, Webb DJ, Whitworth JA 2000 Cortisol inhibits cholinergic vasodilation in the human forearm. Am J Hypertens 13:1155-1160

34. Hadoke PW, Macdonald L, Logie JJ, Small GR, Dover AR, Walker BR 2006 Intra-vascular glucocorticoid metabolism as a modulator of vascular structure and function. Cell Mol Life Sci 63:565-578

35. Ullian ME 1999 The role of corticosteriods in the regulation of vascular tone. Cardiovasc Res 41:55-64

36. Pruessner JC, Wolf OT, Hellhammer DH, Buske-Kirschbaum A, von Auer K, Jobst S, Kaspers F, Kirschbaum C 1997 Free cortisol levels after awakening: a reliable biological marker for the assessment of adrenocortical activity. Life Sci 61:25392549 